\title{
Is a Day I postoperative review following $a b$ interno Xen gel stent surgery for glaucoma needed?
}

This article was published in the following Dove Press journal: Clinical Ophthalmology

\author{
Ayesha Karimi \\ Dan Lindfield \\ Department of Ophthalmology, Royal \\ Surrey County Hospital, Guildford, \\ UK
}

Purpose: To assess whether a first day review is needed following Xen surgery in glaucoma patients.

Patients and methods: We performed a retrospective case note review of all Xen surgeries performed across four centers between August 2015 and May 2017. Intraocular pressure (IOP), number of medications, complications, and all further procedures were recorded.

Results: Two hundred and fifty-nine cases from 226 patients were analyzed, 78 of 259 cases $(30.1 \%)$ had numerical hypotony $(<6 \mathrm{mmHg})$ on Day 1 , but 60 had resolved by Week 1 . Zero cases of hypotony required intervention at Day 1 . Two of 259 cases $(0.8 \%)$ had transient IOP of $\geq 20 \mathrm{mmHg}$ due to air bubble/iris blockage on Day 1 with one case $(0.4 \%)$ requiring iris manipulation at the slit-lamp. One case $(0.4 \%)$ required IOP lowering medications at Day 1 . All other complications and interventions in our series occurred at 1 week or beyond. Day 1 IOP was not shown to be a reliable indicator for outcomes at Week $1\left(r^{2}=0.2155\right)$, Month $1\left(r^{2}=0.0574\right)$, or Month $12\left(r^{2}=0.1580\right)$.

Conclusion: The presence of significant complications requiring intervention at Day 1 was $0 \%$. Only one case $(0.4 \%)$ required topical IOP lowering medication and one case $(0.4 \%)$ needed stent manipulation at Day 1. Day 1 IOP is not a reliable indicator of long-term outcomes in Xen surgeries. Removing Day 1 follow-up would have been safe in our series and it may be more effective to perform the first postoperative review of Xen surgery at Week 1.

Keywords: ab interno, MIGS, gel stent, open angle

\section{Introduction}

Trabeculectomy remains the gold standard for the surgical management of glaucoma but the number of trabeculectomies performed has been declining in the last few decades. ${ }^{1,2}$ Many surgeons are turning to minimally invasive glaucoma surgeries (MIGS) for early to moderate glaucoma. ${ }^{3,4}$ The Xen gel stent (Allergan, Inc., Irvine, CA, USA) is indicated for the management of open-angle non-inflammatory glaucomas and utilizes the ab interno approach ${ }^{5}$ to create a flow pathway from the anterior chamber to the subconjunctival space. Similar to trabeculectomy, ${ }^{6}$ careful patient selection, adjunctive use of antifibrinolytics, ${ }^{7}$ and surgical technique impact the outcome of Xen surgery. The postoperative period however, including the frequency of postoperative visits, adjustment of steroid frequency, and bleb management, plays an equally important role. ${ }^{8,9}$

There is currently no direct comparison of Xen against trabeculectomy published. Several studies have attempted to correlate early postoperative intraocular pressure (IOP) or bleb morphology with long-term outcomes of trabeculectomy. ${ }^{10-13}$ Case series
Correspondence: Ayesha Karimi Department of Ophthalmology, Royal Surrey County Hospital, Guildford, GU2 7XX, UK

Tel +44 (0) I483406895

Fax +44 (0) 1483464189

Email ayeshakarimi@nhs.net 
data may suggest that Xen has a lower incidence of visually threatening complications, and postoperative follow-up has typically included Day 1 review. ${ }^{14-19}$ Routine first day IOP check has been abandoned for phacoemulsification for several reasons that could also apply to MIGS. ${ }^{20-24}$ With low complication rates, improved postoperative outcomes and economical constraints, is Day 1 follow-up required following routine Xen gel stent surgery?

\section{Methods}

We performed a retrospective case note review of all consecutive Xen surgeries undertaken across four centers between August 2015 and May 2017 (as outlined in the multi-center Xen study). ${ }^{19}$ The decision to perform Xen implantation was made by consultant ophthalmic surgeons with a subspecialist interest in glaucoma. Surgery was offered to patients with mild to moderate glaucoma with inadequate IOP control, to avoid polypharmacy or when there was progression of disease despite seemingly adequate IOPs. Informed consent was obtained from all patients undergoing surgery and the audit fell within the ethical framework of the Declaration of Helsinki. No research ethics approval was required for this study. All surgeries were performed by consultant ophthalmic surgeons with a subspecialist interest in glaucoma. All patients received standardized postoperative antibiotic and steroid medications, ie, chloramphenicol drops four times a day for 2 weeks and dexamethasone $0.1 \%$ or prednisolone $1 \%$ drops, 2-hourly for 2 weeks, tapered down depending on postoperative progress. All IOP lowering medications were stopped at the time of surgery. Data were recorded on Microsoft Excel 2016, and statistical analysis was performed using SPSS (IBM Corporation, Armonk, NY, USA). Univariate linear regression was used to assess correlation between IOP at any two timepoints. $P<0.05$ was considered as statistically significant.

\section{Results}

Two hundred and fifty-nine surgeries on 226 patients (Table 1) were performed. Seventy-two cases had simultaneous phacoemulsification, whereas 187 had Xen implantation alone. IOP reduced from a preoperative mean of $19.3( \pm 0.7)$ $\mathrm{mmHg}$ to $14.2( \pm 0.9) \mathrm{mmHg}$ at Month $12(P<0.0001) .{ }^{19}$ Patients were treated with a mean of $2.6( \pm 0.1)$ medications prior to implant surgery compared to $0.8( \pm 0.2)$ medications at Month $12(P<0.0001)$.

\section{Efficacy on Day I}

No correlation was found between Day 1 (or Month 1) and Month 12 IOPs, with significant variability of IOP
Table I Patient demographics

\begin{tabular}{|c|c|}
\hline Number of surgeries & 259 \\
\hline \multicolumn{2}{|l|}{ Age, years } \\
\hline Mean $(95 \% \mathrm{Cl})$ & $74.8(73.4-76.2)$ \\
\hline Range & $37-96$ \\
\hline \multicolumn{2}{|l|}{ Sex, n (\%) } \\
\hline Male & I $44(55.6)$ \\
\hline Female & $115(44.4)$ \\
\hline \multicolumn{2}{|l|}{ Ethnicity, n (\%) } \\
\hline White & $254(98.1)$ \\
\hline Asian Indian & $3(1.2)$ \\
\hline Arab & $2(0.7)$ \\
\hline \multicolumn{2}{|l|}{ Operated eye, n (\%) } \\
\hline Right & $130(50.2)$ \\
\hline Left & $129(49.8)$ \\
\hline \multicolumn{2}{|l|}{ Preoperative IOP, $\mathrm{mmHg}$} \\
\hline Mean $(95 \% \mathrm{Cl})$ & $19.3(18.5-20.0)$ \\
\hline Range & $5-40$ \\
\hline \multicolumn{2}{|c|}{ Number of IOP lowering medications } \\
\hline \multicolumn{2}{|l|}{ preoperatively } \\
\hline Mean $(95 \% \mathrm{Cl})$ & $2.6(2.5-2.7)$ \\
\hline Range & $0-4$ \\
\hline \multicolumn{2}{|l|}{ Surgery type, n (\%) } \\
\hline Xen & $187(72.2)$ \\
\hline Xen + phacoemulsification & $72(27.8)$ \\
\hline \multicolumn{2}{|c|}{ Previous glaucoma intervention, $\mathrm{n}(\%)$} \\
\hline Laser trabeculoplasty & $72(34.4)$ \\
\hline Trabeculectomy & II (4.2) \\
\hline Valve/stent & $7(3.3)$ \\
\hline \multicolumn{2}{|l|}{ Diagnoses, n (\%) } \\
\hline OAG & $208(80.3)$ \\
\hline NTG & $17(6.6)$ \\
\hline PXF & $13(5.0)$ \\
\hline PDS & $6(2.3)$ \\
\hline Trauma & $6(2.3)$ \\
\hline NVG & $5(1.9)$ \\
\hline latrogenic & $\mathrm{I}(0.4)$ \\
\hline Others & $3(1.2)$ \\
\hline \multicolumn{2}{|l|}{ Anesthesia, $\mathrm{n}(\%)$} \\
\hline Sub-Tenon's & $108(4 \mid .7)$ \\
\hline Topical + intracameral & $53(20.5)$ \\
\hline Peribulbar & $34(13.1)$ \\
\hline Unknown & $64(24.7)$ \\
\hline
\end{tabular}

Abbreviations: IOP, intraocular pressure; OAG, primary open angle glaucoma; NTG, normal tension glaucoma; PXF, pseudoexfoliation syndrome; PDS, pigment dispersion syndrome; NVG, neovascular glaucoma.

comparison for each time-point $\left(r^{2}=0.1580\right)$ (Figure 1). Additionally, we found that Day 1 IOP did not have any correlation with outcomes at Week $1\left(r^{2}=0.2155\right)$ or Month 1 $\left(r^{2}=0.0574\right)$.

\section{Safety and intervention on Day I}

Numerical hypotony (IOP $<6 \mathrm{mmHg}$ ) occurred in 90 cases out of 259. Seventy-eight out of these 90 cases $(86.7 \%)$ presented on Day 1 (Table 2), with 3 cases (1.2\%) showing evidence of hypotonous maculopathy. Sixty of these cases $(76.9 \%)$ had resolved by Week 1 with 


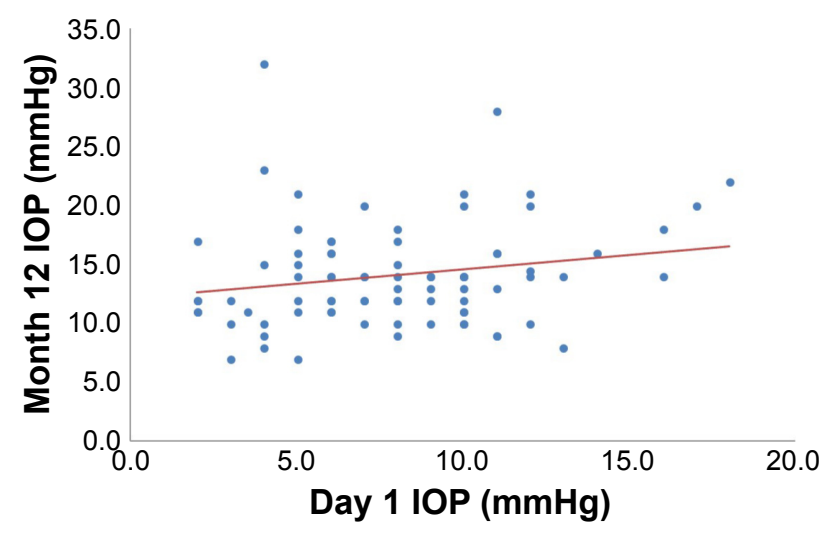

Figure I Scatter plot of Day I and Month I 2 IOP for all Xen surgeries followed up to 12 months $(\mathrm{n}=83)$.

Note: Univariate linear regression analysis: $r^{2}=0.1580, P<0.0001$.

Abbreviation: IOP, intraocular pressure.

observation alone. Two cases required active slit-lamp reformation of the anterior chamber throughout follow-up, but both after Day 1 (Table 3). No cases required treatment for numerical hypotony at Day 1 . Throughout our series, a postoperative IOP spike of $\geq 30 \mathrm{mmHg}$ occurred in 33 cases (12.7\%), but never presented on Day 1. Transient occlusion of the implant leading to an IOP of $\geq 20 \mathrm{mmHg}$ occurred in 2 cases at Day 1. One was due to an air bubble occlusion that resolved spontaneously and another due to iris occlusion, which required stent manipulation at the slit-lamp to remove blockage (Table 3). Large, overhanging dysesthetic blebs developed in 6 cases $(3.9 \%)$ at or beyond Week 1 . There were 6 cases $(2.3 \%)$ of stent erosion/exposure, again all presenting at or beyond Month 1. One case $(0.4 \%)$ of endophthalmitis occurred at 18 months after erosion despite two conjunctival resuturing procedures.

Bleb management was required in $40.9 \%$ of cases throughout our series, ${ }^{19}$ the majority between Month 1 and 3 (modal point being Month 2). Two cases had an additional injection of steroid or 5-fluorouracil at Day 1, both of which were planned prior to surgery due to severe conjunctival inflammation preoperatively (Table 3$)$. One case $(0.4 \%)$ required IOP lowering medications at Day 1 as IOP was not at target in a high-risk eye.

\section{Discussion}

The Day 1 postoperative review for ophthalmic surgery has many benefits including detection of early postoperative complications, reassurance for the patient, and as a trainingaid for junior surgeons..$^{20,21}$ Some surgical complications are however unlikely to be found on the first day, and if complications are detected, it may not be appropriate to treat until later in the postoperative period. Routine first day IOP check has been abandoned for phacoemulsification for several reasons that could also apply to MIGS devices. With increasing pressure on the health care system and increasing workloads of health care professionals, a reasonable balance of frequency of postoperative review needs to be achieved. ${ }^{25}$ The number and timepoints of postoperative follow-ups should be devised so that the number of examinations are low and the chance of early intervention in case of serious complications is high.

In this study, we presented a multi-center case series of the Xen gel stent in a heterogeneous mix of glaucoma patients, translatable to most surgeons' cohorts. We found a trend suggesting that the Day 1 review could be discarded from standard care and this is likely to have cost saving and clinical capacity benefits. The study was however retrospective in nature, with 89 patients completing 12 months follow-up. We had a range of baseline IOPs, and it should be noted that there will be a degree of selection bias as the decision to offer Xen implantation was determined by individual surgeons, without standardized inclusion or exclusion criteria. A prospective study with strict inclusion and exclusion criteria would help assess the need for Day 1 review more accurately.

Table 2 Frequency and timepoint of postoperative complications found following Xen surgery ( $\mathrm{n}=259)$

\begin{tabular}{|c|c|c|c|c|}
\hline Complications & Day I & Week I & Month I & $\begin{array}{l}\text { Beyond } \\
\text { Month I }\end{array}$ \\
\hline Numerical hypotony $(\mathrm{IOP}<6 \mathrm{mmHg})$ & 78 & 9 & I & 2 \\
\hline IOP spike ( $\geq 30 \mathrm{mmHg})$ & 0 & 6 & 10 & 17 \\
\hline Transient implant occlusion, eg, iris, blood (causing IOP $\geq 20 \mathrm{mmHg}$ ) & 2 & I & 6 & I \\
\hline$\geq 2$ Snellen lines vision loss lasting $>I$ month & 0 & 0 & 0 & 9 \\
\hline Large dysesthetic bleb & 0 & I & 2 & 3 \\
\hline Implant exposure & 0 & 0 & 3 & 3 \\
\hline Hypotonous maculopathy & 3 & I & 1 & 0 \\
\hline Choroidal effusion lasting $>I$ month & 0 & 0 & 0 & 4 \\
\hline Endophthalmitis & 0 & 0 & 0 & 1 \\
\hline Central retinal vein occlusion & 0 & 0 & 0 & I \\
\hline
\end{tabular}

Abbreviation: IOP, intraocular pressure. 
Table 3 Frequency and timepoint of further procedures or treatment required following Xen surgery $(n=259)$

\begin{tabular}{|c|c|c|c|c|}
\hline Procedures & Day I & Week I & Month I & $\begin{array}{l}\text { Beyond } \\
\text { Month I }\end{array}$ \\
\hline Bleb management (needling \pm antimetabolite) & $2^{\mathrm{a}}$ & 21 & 75 & 129 \\
\hline Intraocular pressure lowering medications & 1 & 20 & 46 & 136 \\
\hline Secondary filtration surgery & 0 & 3 & 5 & 16 \\
\hline Xen/bleb revision surgery & 0 & 0 & 5 & 11 \\
\hline Lancing of large bleb & 0 & 0 & 5 & 4 \\
\hline Implant manipulation at slit-lamp & 1 & 0 & 0 & 0 \\
\hline Slit-lamp reformation of the anterior chamber & 0 & 1 & 0 & I \\
\hline Endoscopic cyclophotocoagulation & 0 & 0 & 0 & 5 \\
\hline Iridoplasty/iridotomy & 0 & I & 0 & 3 \\
\hline Selective laser trabeculoplasty & 0 & 0 & I & 0 \\
\hline Micropulse laser trabeculoplasty & 0 & 0 & 0 & 1 \\
\hline Laser gonioplasty & 0 & 0 & 1 & 0 \\
\hline
\end{tabular}

Note: aPlanned procedure scheduled prior to surgery due to severe conjunctival inflammation.

We did not find that Day 1 review was a reliable predictor of long-term outcomes. This echoes no correlation between early IOPs with 1 -year outcomes for trabeculectomy. ${ }^{26}$ Additionally, the delta change in IOP from Day 1 to Week 1 did not indicate how the stent would perform long-term. For example, two stents with IOPs of $12 \mathrm{mmHg}$ at Week 1: case one had an IOP of $4 \mathrm{mmHg}$ at Day 1, whereas case two had an IOP of $12 \mathrm{mmHg}$ at Day 1. The cases where this rapid increase in IOP was observed from Day 1 to Week 1 were not found to be more likely to fail or need further intervention. The change in Day 1 to Week 1 IOP did not follow any statistically significant pattern with Month 12 IOP, illustrating the lack of predictability from the Day 1 assessment.

While numerical hypotony occurred in $34.7 \%$ of cases, no cases required intervention at Day 1 . The authors found numerical hypotony to be common with the stent as the needle of the injector that encloses the stent has a much larger diameter than that of the stent; therefore, a larger tract is formed for aqueous to flow around the stent in the early postoperative period. As the sclera shrinks and conforms around the stent, flow is more controlled. There were no cases of corneal wound leakage in our study, and low IOPs on Day 1 were not due to leakage from the incision sites.

In our series, 257 of all 259 cases (99.2\%) did not need any further procedure or adjustment at Day 1 . IOP lowering medications were started for one case $(0.4 \%)$ at Day 1. This case had a preoperative IOP of $33 \mathrm{mmHg}$ on three medications plus oral acetazolamide and continued to have a raised IOP at $27 \mathrm{mmHg}$ on Day 1 postoperatively - this was evidently a high-risk case, which would not be classified as routine. One case $(0.4 \%)$ required iris manipulation to remove blockage of the stent. In this case, it was due to placement of the stent too posteriorly and this was noted on gonioscopy during surgery. Clinicians should consider Day 1 review for any on-table complications such as difficult stent priming, significant hyphema or conjunctival buttonhole, or in high-risk cases.

For routine cases however, it may be worth considering performing the first postoperative review at Week 1. Six of the 33 (18.2\%) IOP spikes occurred at Week 1, where none had occurred on Day 1. Frequency of unplanned bleb management was 0, 21, 75, and 129 modulations at Day 1, Week 1, Month 1, and beyond, respectively. IOP lowering medications were started for 20 cases $(7.8 \%)$ at Week 1 vs one case $(0.4 \%)$ at Day 1 . Secondary filtration surgery and anterior chamber reformation were also performed at Week 1 and neither considered at Day 1. All other further procedures occurred beyond Week 1. For routine Xen cases, we suggest arranging the first postoperative visit at 1 week, as this may give a better indication of long-term IOP as well as being a more effective period to manage complications.

\section{Conclusion}

Two hundred and fifty-seven of 259 Xen surgeries (99.2\%) did not require further intervention at Day 1 . The two cases $(0.8 \%)$ that needed intervention at Day 1 were both high-risk cases recognized preoperatively or during surgery. Day 1 IOP did not show any correlation with outcomes at Week 1, Month 1 or Month 12 and was not a reliable indicator of longterm outcomes. The evidence from our series suggests that Day 1 review could be discarded for routine Xen implantation, and it may be more effective for the first postoperative review of Xen surgery to take place at Week 1. Day 1 review should be reserved for high-risk cases.

\section{Acknowledgments}

We are very thankful to Pieter Gouws who acquired the data at Conquest Hospital; Andrew Turnbull, Abdul Hanifudin, 
Nishani Amerasinghe, and Aby Jacob who acquired the data at University Hospital Southampton; and Chrys Dimitriou, Bhairavi Bhatia, and Mahmoud Radwan who acquired the data at Essex County Hospital.

\section{Author contributions}

Both authors contributed towards study design, data acquisition and analysis, drafting and critically revising the paper, gave final approval of the version to be published, and agree to be accountable for all aspects of the work.

\section{Disclosure}

DL reports previously receiving honoraria from Allergan, Alcon, Endo Optiks, Thea, MSD, BVI Visitec, and Santen as well as serving on the advisory panel for Allergan outside of this work. The authors report no other conflicts of interest in this work.

\section{References}

1. Ramulu PY, Corcoran KJ, Corcoran SL, Robin AL. Utilization of various glaucoma surgeries and procedures in Medicare beneficiaries from 1995 to 2004. Ophthalmol. 2007;114(12):2265-2270.

2. Arora KS, Robin AL, Corcoran KJ, Corcoran SL, Ramulu PY. Use of Various Glaucoma Surgeries and Procedures in Medicare Beneficiaries from 1994 to 2012. Ophthalmol. 2015;122(8):1615-1624.

3. Dang Y, Waxman S, Wang C, et al. Rapid learning curve assessment in an ex vivo training system for microincisional glaucoma surgery. Sci Rep. 2017;7(1):1605.

4. Fallano K, Bussel I, Kagemann L, Lathrop KL, Loewen N. Training strategies and outcomes of $a b$ interno trabeculectomy with the trabectome. F1000Res. 2017;6:67.

5. Lewis RA. Ab interno approach to the subconjunctival space using a collagen glaucoma stent. J Cataract Refract Surg. 2014;40(8):1301-1306.

6. Esfandiari H, Pakravan M, Loewen NA, Yaseri M. Predictive value of early postoperative IOP and bleb morphology in Mitomycin-C augmented trabeculectomy. F1000Res. 2017;6:1898.

7. Tan SZ, Walkden A, Au L. One-year result of XEN45 implant for glaucoma: efficacy, safety, and postoperative management. Eye (Lond). 2018; 32(2):324-332.

8. Marquardt D, Lieb WE, Grehn F. Intensified postoperative care versus conventional follow-up: a retrospective long-term analysis of 177 trabeculectomies. Graefes Arch Clin Exp Ophthalmol. 2004;242(2): 106-113.

9. Kirwan JF, Lockwood AJ, Shah P, et al; Trabeculectomy Outcomes Group Audit Study Group. Trabeculectomy in the 21st century: a multicenter analysis. Ophthalmol. 2013;120(12):2532-2539.

10. Alwitry A, Moodie J, Rotchford A, Abedin A, Patel V, King AJ. Predictive value of early IOP in mitomycin-C augmented trabeculectomy. J Glaucoma. 2007;16(7):616-621.

Clinical Ophthalmology

\section{Publish your work in this journal}

Clinical Ophthalmology is an international, peer-reviewed journal covering all subspecialties within ophthalmology. Key topics include: Optometry; Visual science; Pharmacology and drug therapy in eye diseases; Basic Sciences; Primary and Secondary eye care; Patient Safety and Quality of Care Improvements. This journal is indexed on
11. Rong SS, Feng MY, Wang N, et al. Can early postoperative intraocular pressure predict success following mitomycin-C augmented trabeculectomy in primary angle-closure glaucoma. Eye (Lond). 2013; 27(3):403-409.

12. Okimoto S, Kiuchi Y, Akita T, Tanaka J. Using the early postoperative intraocular pressure to predict pressure control after a trabeculectomy. J Glaucoma. 2014;23(6):410-414.

13. Rong SS, Meng HL, Fan SJ, et al. Can intraoperative intraocular pressure during primary trabeculectomy predict early postoperative pressure? J Glaucoma. 2014;23(9):653-657.

14. Galal A, Bilgic A, Eltanamly R, Osman A. XEN Glaucoma Implant with Mitomycin C 1-Year Follow-Up: result and complications. J Ophthalmol. 2017;2017:5457246.

15. Stalmans I, Fea A, Reitsamer H, Lavin C. A minimally invasive approach to sub-conjunctival outflow: 1 year results of an ab-interno gelatin stent in combination with preoperative MMC injection for the treatment of primary open angle glaucoma. Acta Ophthalmol. 2015;93.

16. Pérez-Torregrosa VT, Olate-Pérez Á, Cerdà-Ibáñez M, et al. Combined phacoemulsification and XEN45 surgery from a temporal approach and 2 incisions. Arch Soc Esp Oftalmol. 2016;91(9):415-421. Spanish.

17. Sheybani A, Ahmed I. Ab Interno Gelatin Implant with Mitomycin-C Combined with Cataract Surgery for Treatment of Open-angle Glaucoma: 1 Year Results. Paper presented at: ASCRS; 2015; USA.

18. De Gregorio A, Pedrotti E, Russo L, Morselli S. Minimally invasive combined glaucoma and cataract surgery: clinical results of the smallest ab interno gel stent. Int Ophthalmol. 2018;38(3):1129-1134.

19. Karimi A, Lindfield D, Turnbull A, et al. A multi-centre interventional case series of 259 ab-interno Xen gel implants for glaucoma, with and without combined cataract surgery. Eye. Epub 24 October 2018.

20. Chatziralli IP, Sergentanis TN, Kanonidou E, Papazisis L. First postoperative day review after uneventful phacoemulsification cataract surgery: is it necessary? BMC Res Notes. 2012;5:333.

21. Tan JH, Newman DK, Klunker C, Watts SE, Burton RL. Phacoemulsification cataract surgery: is routine review necessary on the first post-operative day? Eye (Lond). 2000;14(Pt 1):53-55.

22. Tinley CG, Frost A, Hakin KN, Mcdermott W, Ewings P. Is visual outcome compromised when next day review is omitted after phacoemulsification surgery? A randomised control trial. Br J Ophthalmol. 2003;87(11):1350-1355.

23. Alwitry A, Rotchford A, Gardner I. First day review after uncomplicated phacoemulsification: is it necessary? Eur J Ophthalmol. 2006; 16(4):554-559.

24. Clinical Guidelines - The Royal College of Ophthalmologists [online]. The Royal College of Ophthalmologists, London, UK. 2010. Available from: https://www.rcophth.ac.uk/standards-publications-research/ clinical-guidelines/. Accessed August, 2017.

25. Gupta A, Vernon SA. Is the 1-day postoperative IOP check needed post uncomplicated phacoemulsification in patients with glaucoma and ocular hypertension? Eye (Lond). 2015;29(10):1299-1307.

26. Polikoff LA, Taglienti A, Chanis RA, et al. Is intraocular pressure in the early postoperative period predictive of antimetabolite-augmented filtration surgery success? J Glaucoma. 2005;14(6):497-503.

\section{Dovepress}

PubMed Central and CAS, and is the official journal of The Society of Clinical Ophthalmology (SCO). The manuscript management system is completely online and includes a very quick and fair peer-review system, which is all easy to use. Visit http://www.dovepress.com/ testimonials.php to read real quotes from published authors. 